\title{
A STUDY OF THE USE OF ELECTRONIC ENVIRONMENTAL CONTROL SYSTEMS BY SEVERELY PARALYSED PATIENTS
}

\author{
By J. G. Parish, M.D., F.R.C.P.(C), D.Phys.Med. \\ Passmore Edwards Medical Rehabilitation Centre, Clacton-on-Sea, Essex, England
}

\begin{abstract}
The types of environmental control systems issued by the Department of Health and Social Security in England are described. The extent to which the apparatus is used by patients in the north-east Thames region is recorded according to the location (sitting room, bedroom, etc.), the number of hours in use and telephone calls made.
\end{abstract}

Key words: Quadriplegia; Rehabilitation; Electronics, medical; Environmental control systems.

\section{Introduction}

IN 1960 a research engineer on a visit to Stoke Mandeville Hospital was impressed by the efforts of a young Rhodesian tetraplegic patient to summon attention by means of a whistle, which the nursing staff had suspended above his lips (Maling, 1974). This incident stimulated several years of experimental work, resulting in the production of the first electronic selector unit, which gives patients with minimal movement below the neck the opportunity to regain some control over their environment by being able to operate various electrical gadgets. The selector responds to pressure/suction changes from the mouth by means of a pipe stem. If there is sufficient movement available it will also respond to pressure from the arm or foot through a pneumatic pad or to electrical changes induced by the closure of a microswitch. The movement of the selector is indicated on a visual display panel by a light, which moves from one position to another. Each position represents an electrical device, such as a lamp or television set. The patient can, by opening the microswitch or altering the pressure in the pneumatic system, turn the device on or off, when the selector reaches the required position. Using engineering jargon the instrument was called Patient-Operated Selector Mechanism (POSM) from which was derived the rehabilitation-orientated term Possum, meaning 'I am able'.

After clinical trials under the auspices of the Polio Research Fund the Ministry of Health (now the Department of Health and Social Security-DHSS) was ready in 1966 to finance the prescription of Possum units for NHS patients. Applications for Possum were processed by one or more Assessors in each region of the National Health Service with the assistance of the patient's medical and social services advisers at domicilary case conferences (Parish, 1974).

Since 1966 several types of environmental control (EC) systems have been made available through the DHSS scheme:

I. The original Possum PSUI unit could operate an alarm, aid bell, electric fire, connect a loudspeaker telephone to the operator and switch on seven additional items, which could be varied as required by the patient. In I97I a self-dialling system was incorporated in the mechanism. These units are now being phased out of service; 
2. The Possum $\mathrm{PSU}_{3}$ was introduced in 1975 and includes an improved telephone dialling system and two pre-set telephone numbers, which the selector will dial automatically. The selector will control over 40 operations including changing television and radio channels, controlling intercoms to several rooms as well as switching on individual electrical items;

3. System 7 was introduced in the same year. This device would contact the telephone operator and operate eight other items. The manufacturer went out of business the following year and the equipment is now obsolete.

In addition trials of the Possum PSU2 (Possum Link) were carried out in the north-east Thames region. The equipment was subsequently supplied from Local Authority Social Services funds. This unit consists of a bank of six switches of a lever or tumbler type and a microphone for intercom. to the front door or another room. It is suitable for patients who have a moderate degree of arm reach and hand control.

\section{Method}

During the period of Io years from March 1967 to March 1977, I59 patients have been assessed for environmental control (EC) aids under the DHSS scheme in the territory of the North-East Thames Regional Health Authority, which serves a population of 3.7 million. A total of IOI patients were recommended for

\section{TABLE I}

Types of environmental control system provided for patients in north-east Thames region $1967-77$

\begin{tabular}{cc}
\hline $\begin{array}{c}\text { Type of } \\
\text { control system }\end{array}$ & $\begin{array}{c}\text { No. of } \\
\text { units supplied }\end{array}$ \\
\hline Possum PSUI & 76 \\
Possum PSU3 & 10 \\
System 7 & 7 \\
Possum PSU2 & 8 \\
Total & IOI \\
\hline
\end{tabular}

EC systems and the type of unit supplied is shown in Table I. There were a number of reasons why the remaining patients were not supplied with EC units and these can be listed as follows:

I. the patients were mobile in wheelchairs and had sufficient reach to operate electrical switches unaided;

2. they required only simple aids such as an intercom. system to the front door and a door opening device or a loudspeaker telephone; or

3. they were mentally incapable of operating the selector timing mechanism or were frightened of complex electrical equipment.

A survey is continuing into the use of various EC systems and it is becoming more detailed as the enquiry develops. Information is being collected concerning the number of items of electrical equipment the patient is actually operating, the location of the control input (in a living room, bedroom or bedsitting room), and 
the total hours per day the equipment is in use in each location, while the patient is alone as well as when an attendant is available. The use of the telephone is also being studied, the number of incoming calls being recorded as well as the number of calls made by dialling and through an operator.

\section{Diagnosis}

\section{Results}

The diagnoses in the first hundred patients supplied with EC systems is shown in Table II. Many of the patients with rheumatoid arthritis had tetraparesis as a result of a myelopathy due to subluxation of the cervical spine.

\section{TABLE II}

Diagnosis in patients supplied with electronic environmental control systems

\begin{tabular}{lc}
\multicolumn{1}{c}{ Disease } & No. of patients \\
\hline Multiple sclerosis & 36 \\
Rheumatoid arthritis & I4 \\
Traumatic tetraplegia & IO \\
Poliomyelitis & 9 \\
Muscular dystrophy & 7 \\
Motor neurone disease & 5 \\
Benign spinal muscular atrophy & 3 \\
Syringomyelia & 3 \\
Cerebral palsy & 2 \\
Miscellaneous neurological conditions & II \\
Total & IoO \\
\hline
\end{tabular}

TABLE III

Items controlled by environmental control systems in a survey of 57 patients

\begin{tabular}{lclc}
\hline \multicolumn{1}{c}{ Item } & $\begin{array}{c}\text { No. of } \\
\text { patients } \\
\text { using item }\end{array}$ & \multicolumn{1}{c}{ Item } & $\begin{array}{c}\text { No. of } \\
\text { patients } \\
\text { using item }\end{array}$ \\
\hline Lamp & 5 I & Tape recorder & I I \\
Call buzzer & 49 & Talking book & 9 \\
Intercom. to front door & 49 & Internal intercom. & 7 \\
Front door lock release & 49 & Respirator control & 4 \\
Internal alarm & 48 & Typewriter control & 2 \\
Television & 47 & Bed control & I \\
External alarm & 40 & Page turner & I \\
Telephone & 40 & Curtains & I \\
Radio & 38 & Ripple mattress & I \\
Fire & 3 I & Teasmade & I \\
Fan & I4 & 'Logs' of gas fire & \\
Record player & I2 & & \\
\hline
\end{tabular}




\section{Number of Items Operated}

Initially 57 patients were visited and a list of items of equipment operated is recorded in Table III. The list is divided into two groups consisting of ten items frequently controlled by EC systems and I 3 items only occasionally connected to the selector. This distribution could be due to the limitation of the Possum PSUI selector to control only i I items. However the distribution of the number of items operated by the 48 PSUI users shows that only 25 per cent of these patients fully utilise the available outlets (Table IV).

\section{TABLE IV}

Maximum number of items operated by Possum PSUI users

\begin{tabular}{cc}
\hline No. of items & No. of patients \\
\hline 4 & 3 \\
5 & 0 \\
6 & 2 \\
7 & I \\
8 & I \\
9 & 8 \\
IO & I2 \\
I I & 48 \\
Total & \\
\hline
\end{tabular}

\section{Location of Selector and Use of Telephone}

During the survey it has become apparent that the selector is being used more intensively when it is situated in a bedsitting room than when it is located in the living room and is being operated from a separate living room and bedroom. In I 8 PSUI users this difference has been observed by recording the number of devices in use during the day and the number available at night or when the patient is confined to bed. The number of hours the equipment is set up for use has also been estimated. From Table $\mathrm{V}$ it can be seen that the number of items operated

\section{TABLE V}

Effect of location of selector on number of items controlledhours in use and use of telephone

\begin{tabular}{ccccc}
\hline Location & $\begin{array}{c}\text { Mean no. of } \\
\text { items in use }\end{array}$ & Day N Night & $\begin{array}{c}\text { Total hours } \\
\text { in use } \\
\text { (mean) }\end{array}$ & $\begin{array}{c}\text { No. of } \\
\text { telephone calls } \\
\text { per week } \\
\text { (mean) }\end{array}$ \\
\hline $\begin{array}{c}\text { Bedsitting } \\
\text { room }\end{array}$ & 9 & 9 & I9 & 42 \\
$\begin{array}{c}\text { Separate sitting } \\
\text { and bedroom }\end{array}$ & 8 & 4 & I5 & 13 \\
\hline
\end{tabular}


from a separate bedroom is only half the number in use during the day in the living room or operated at night from a bedsitting room. The mean duration of operation is also increased by about 4 hours per day when the selector is situated in a bedsitting room. About three times as many telephone calls are made from a bedsitting room than from separate rooms. In many cases this may be due to the availability of the telephone in the evening, when calls are cheaper.

\section{Discussion and Conclusions}

This survey is being carried out during the introduction of the Possum $\mathrm{PSU}_{3}$ selector, which has more outlets available for operation of electrical equipment than any patient is likely to need. It would appear that fewer than 25 per cent of patients may need the more elaborate selector because their PSUI is fully utilised. However, the $\mathrm{PSU}_{3}$ has been exchanged for the PSUI in cases where the automatic dialling facility was considered an essential facility in an emergency (for patients on respirators) or because the patients had difficulty in dialling telephone numbers sufficiently rapidly to complete dialling before the telephone exchange circuits had terminated the call. This may happen if a number contains several 9s or os. One patient was operating five additional items and another patient six additional items independently of their PSUI units by individual switches, thus indicating the need for the extra outlets provided by the PSU3 system. The demand for additional outlets is likely to increase in the future as the use of sophisticated electrical equipment such as cassette players and tape recorders becomes more widespread in the home.

The increased use of EC systems by patients in a bedsitting room has important applications when the home care of a tetraplegic patient is being planned. In practice this may involve removal of a wall between two rooms to provide a living area and a sleeping and self-care area or building an extension with the two areas partly divided by a partition, yet allowing easy access to both areas for a patient in an electric wheelchair. This arrangement permits the indicator panel to be placed so that it can be seen from both areas or for the electric wheelchair to be moved to within sight of the indicator. When a patient has a separate living room and bedroom the indicator panel is normally situated in the living room, so that when operating the system from the bedroom the patient has to judge the position of the selector scan by counting the sounds of the selector mechanism. These sounds can be amplified by a tone generator, so that operation of items at the beginning of the scan is fairly easy to carry out, but more complex activities such as dialling telephone numbers are beyond the capability of many patients. For many patients the limited environmental control from the bedroom is not a serious hardship, if there is a spouse at hand at night and the day is spent within sight of the selector in the living room. However, there is a number of patients, who regularly or periodically spend part of the day in bed, where their ability to make use of their EC selector is limited. Duplication of the indicator panel for this situation has not proved practicable. As the telephone is the facility which is most appreciated by the majority of patients, further development of the selector systems is needed so that the dialling difficulties can be solved.

The effect of the provision of an EC system on a patient's morale is difficult to measure, but in most cases it is considerable, so that the equipment becomes an essential item of home care. The strain on the attendant is also reduced as the patient can be left alone in the knowledge that help can be obtained by telephone or an alarm if an emergency arises-one patient thwarted an attempted burglary 
and another summoned help when there was a fire in the kitchen while her husband was shopping. Unfortunately there have been rare instances when a spouse has refused to allow a patient the increased independence these systems permit, but in nearly all the patients visited in this survey the improvement in family relationships provided sufficient evidence that the supply of EC equipment is an essential ingredient in the care of many tetraplegic patients at home.

\section{RÉSUMÉ}

Les systèmes de contrôle de l'environnement mis en circulation par le Département de Santé et de Sécurité Sociale en Angleterre sont détaillés. Le point auquel les malades de la Région North East Thames emploient l'appareil est enregistré selon la situation (le salon, la chambre à coucher, etc.), les heures d'emploi, et le nombre d'appels de téléphone.

\section{ZUSAMMENFASSUNG}

Es werden die Arten eines Kontroll-systems beschrieben, das die nähere Umgebung der Patienten überwachen kann, und das von der Abteilung für Gesundheit und sozialer Sicherheit Englands eingeführt wurde. Der registrierte Umfang, in dem die Apparaturen von den Patienten der nordöstlichen Themse-region benutzt wurden, war abhängig von den Örtlichkeiten (Wohnzimmer, Schlafzimmer usw.) und der Zeit, in der sie benutzt wurden, und der Auzahl der Telephon-gespräche.

\section{REFERENCES}

Maling, R. (I974). In K. Copeland (ed.), Aids for the Severely Handicapped, p. 22. Sector Publishing, London.

Parish, J. G. (I974). The British case conference method for the supply of electronic environmental controls. Proceedings of the Seminar on Electronic Controls for the Severely Physically Handicapped, Kinsman Foundation of British Columbia, Vancouver, B.C. 